\title{
IoT-School Attendance System Using RFID Technology
}

\author{
https://doi.org/10.3991/ijim.v14i14.14625 \\ Hicham El Mrabet ${ }^{(凶)}$, Abdelaziz Ait Moussa \\ Mohammed First University, Oujda, Morocco \\ hi.elmrabetegmail.com
}

\begin{abstract}
Nowadays, the world has known great changes which accelerated the mode of life. Students, on their part have become to expect a stimulating and simple learning experience which takes into consideration this quick pace and helps them solve the stereotypical problems of learning. The analyses conducted in this paper revealed that the recording of attendance in classrooms is done at the expense of the teaching- learning time. Therefore, the article at hand seeks to investigate an effective means to record attendance in a way which doesn't hinder learning. Differently put, the educational and administrative staffs need to find an effective way to record students' attendance at presential at the beginning of each learning session without affecting the time allotted to teaching and learning. This article presents and discusses the smart attendance monitoring system in smart classroom as a means to reduce the dropout rate, using connected objects and RFID technology. This system can facilitate the recording of students' attendance via the Internet of things (IoT) at presential while transmitting attendance record to the administration. At the same time, parents can keep track of their children's attendance to classes through a notification they receive via Email or SMS. In addition, the system automatically sends missed lessons to absent students.
\end{abstract}

Keywords - School attendance system, Smart classroom, Smart Education, RFID Tags, Internet of things.

\section{Introduction}

Nowadays, multiple information and communication technologies (ICT) have the potential to develop society and directed towards several domains such as health, industry, and social life. In recent time, their use progresses considerably to cover education field, and have a holistic impact on the learning outcomes [1]. In the context of the development of traditional practices towards modern education, ICT have become tools which characterize a whole generation henceforth defined as 'digital natives', who have gone far from textbooks and similar traditional tools. A number of digital tools, mobile devices and platforms are now available to education fields [2]. It can therefore rethink education and assessment practices, methods and educational environments [3]. Therefore, technology should be fully integrated not only in learning but in class management as well. Along the same line of thought, the Internet of Things (IoT) [4], which has invaded many areas of our daily lives such as industry, 
energy, health, and transportation, is now firmly imposing itself in the educational field [5] [6]. It has created new methods of interaction between students, teachers and learning environment to improve school performances and thus contribute to enhancing learning and to enable mobility and interaction with physical spaces [7] [8]. The application of IoT in learning environments can be a major support for students as it can give students the opportunity to repeat experiences without damage to property or cost and can interact with smart devices to build knowledge and skills [9] [10]. In this study, we focus on the adaptation level of smart management systems and the uses of IoT technology in the automatic attendance system. It is an attempt to provide an adapted and efficient framework for attendance recording and preprocessing in school. The implementation of smart attendance system creates opportunities to improve the levels of smartness and develop the ICT skills. Above all, it aims at solving many attendance problems while preserving the learning time.

The objective is to simplify the process of monitoring attendance in high school and to explore ways to decrease absenteeism and to strengthen the collaboration between parents and school. Given the fact that dropping out of schools is still high in Moroccan schools, the present study is meant to enrich the aforementioned research by building a smart system for the high schools using Radio Frequency Identification (RFID) [11]. RFID technology is fundamental for the realization of IoT because it allows to link "things" to their virtual identity on the Internet [12]. Finally, the study will experiment the IoT attendance system in some classes of higher school to check our system performance.

This article will be structured as follows: Section 2 describes the background of our study and explains a questionnaire to conduct a descriptive analysis to understand the most important barriers to students monitoring attendance. Section 3 introduces and compares related work in this field and analyzes various technology used in attendance systems. Section 4 describes our proposed model and theoretical framework. Section 5 analyzes the experimental results of our system and their interpretations. At the end, we will give some suggestions for future research.

\section{Background}

\subsection{Internet of Things in education}

Nowadays, technological progress and the internet revolution has spawned new concepts, and among these concepts, there was the arrival of the Internet of Things (IoT). The term IoT was first coined in 1999 by Kevin Ashton and is defined as a global network infrastructure that connects many devices with the Internet, to exchange information and make smart recognition [13]. The IoT is a new paradigm where everything can be interconnected with other things to directly identify physical objects and thus be able to transfer, store, and process the information between physical and virtual worlds anytime and anywhere [14]. IoT does not only revolutionize our social life, it also has the potential to add other dimensions by enabling smart learning 
using smart environment in order to increase self-awareness, skills, and knowledge of the learners.

Via IoT, the educational system offers permanent opportunities for smart learning environments that achieve appropriate knowledge, self-learning and self-motivated [15]. A smart learning environment gives the learner the possibility to be a partner in knowledge. In other words, both teachers and students contribute to the building of knowledge which boosts the learners' self-esteem. Smart learning environments based on the IoT which allows various physical things (smartphone, smart student card, tablets, smart board, and digital textbooks) to connect with other mobile things can drastically change our traditional schools, and create free interaction between learners and objects [16]. In addition, smart learning goes beyond the traditional schools, students have access to unlimited digital resources from everywhere. Smart learning which can be described as a combination of multiple technologies and methods in a complementary system based in four pillars can be depicted in Figure 1.

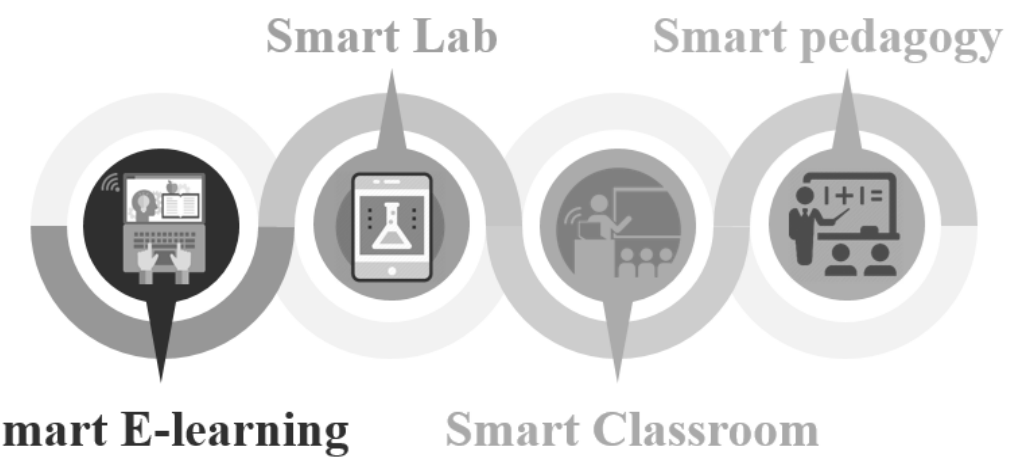

Fig. 1. Smart learning environment.

The research in smart learning fields has mainly concentrated to create smart environments by using smart technology and smart pedagogy [17]. Furthermore, different smart learning environments evolve at a rapid pace, such as smart campuses [18] that help teachers, students and superintendent to automate the process of education [19], smart school guidance to reduce poor orientation and create an environment conducive to the successful of school guidance [20], and smart attendance monitoring to track attendance of the students, as it will be discussed in the section 3. Creating a smart attendance system means not only using smart technologies to help teachers manage the class, but also including a concrete framework to support define the purpose of implementing the technology [21], for this purpose, we used in our research a questionnaire to diagnose the causes of absenteeism, and all methods for treating absence in the classroom. 


\subsection{School attendance survey}

In order to understand and know the most important barriers to monitoring attendance in Moroccan schools, we established the questionnaire as an essential tool. The study targeted about 411 teachers and superintendent at different school levels. This survey aims to study the factors of school absenteeism by identifying the methods of treating absenteeism in school. Our survey is a collection of questions asked repetitively to a sample of teachers to generate information on treating absenteeism in school. Among the most important questions asked, we cite:

- Does the superintendent inform the family in real time?

- Is there a weak link between family and school?

- Would teachers notify the family while the student is absent?

- Is there a failure to apply the absence rules in school?

- Is there fraudulent of student absenteeism?

- Will frequent student absences lead to poor results?

- Is collecting absence data very difficult?

Table 1. Information about the sample

\begin{tabular}{|c|c|l|c|l|}
\hline Teaching level & Gender & \multicolumn{1}{|c|}{ Degree } & Average students & \multicolumn{1}{c|}{ Task duration } \\
\hline \multirow{2}{*}{ Elementary School } & $65 \mathrm{~F}$ & 119 Teachers & $36 /$ class & $(4-6) \mathrm{min} /$ class \\
\cline { 2 - 5 } & $58 \mathrm{M}$ & 04 Superintendents & 500 & $(15-20) \mathrm{min} / \mathrm{All}$ \\
\hline \multirow{2}{*}{ Middle Schools } & $70 \mathrm{~F}$ & 90 Teachers & $34 / \mathrm{class}$ & $(4-6) \mathrm{min} /$ class \\
\cline { 2 - 5 } & $55 \mathrm{M}$ & 08 Superintendents & 500 & $(30-40) \mathrm{min} / \mathrm{All}$ \\
\hline \multirow{2}{*}{ High Schools } & $79 \mathrm{~F}$ & 80 Teachers & $32 / \mathrm{class}$ & $(4-6) \mathrm{min} /$ class \\
\cline { 2 - 5 } & $84 \mathrm{M}$ & 10 Superintendents & 500 & $(30-40) \mathrm{min} / \mathrm{All}$ \\
\hline
\end{tabular}

Table 1 shows the information about the sample and some summaries extracted from the survey. The questionnaire was concerned with the impact of absenteeism, recording duration, organization and methods of attendance in classroom.

It is obvious that the information of students' absenteeism is influenced by factors which include family factors and social factors. It was found that over $(60 \%)$ of frequent absences are a result of poor communication between the family and the school, more than $(65 \%)$ of failure to apply the specified rules of absence, whereas (80\%) demonstrated fraudulently absenteeism. 


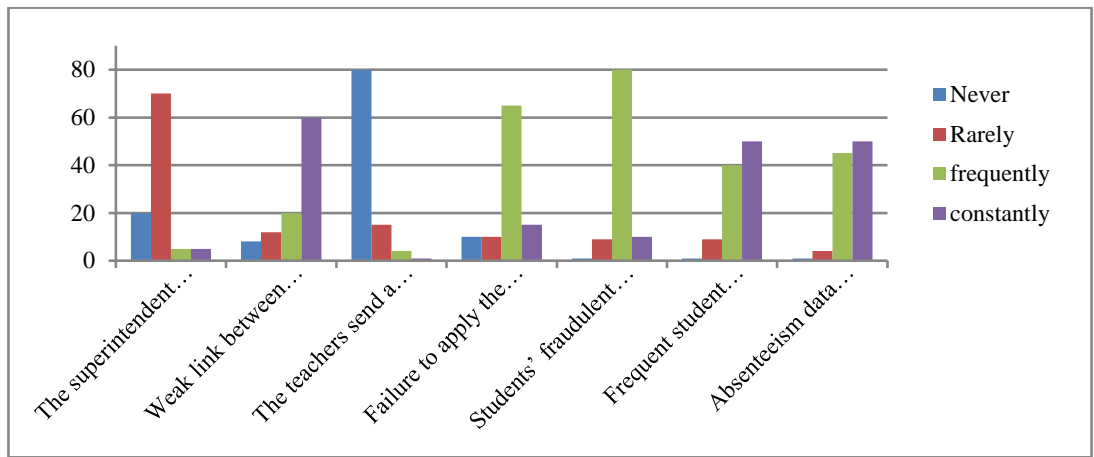

Fig. 2. Degrees of influence on the reasons for the student's absence.

The results shown in Figure 2 indicate that a total of 7 factors have different degrees of influence on student absenteeism, time allotted to learning and the quality of learning. Data from this survey will be used in ICT studies, which will help develop sound management systems, design educational programs and smart services.

A summary of the survey results indicates that Moroccan schools need to develop an effective system to record students' attendance without affecting learning time.

\section{$3 \quad$ Related Work}

Our main criterion is to analyze all studies that have included IoT technology concerning the monitoring of the student attendance system and to choose the best technology in relation to quality and efficiency. Several studies have proposed different approaches and methods to the intelligent monitoring system.

Recently, educational institutes are seeking to improve their attendance system by using new technologies that can help them to record attend on time. Among these technologies we quote Radio Frequency Identification (RFID). It is becoming more popular in the field of detection [22], and consists of an RFID tag and a RFID reader as shown in Figure 3. The RFID provide an efficient method of school monitoring. For instance, Shah S. N. et al. [23] proposed a smart attendance system using RFID tags which allow schools to supervise the student attendance in and out of the class and fetching student data to make it available to teachers / staff anytime and anywhere.

Ayu M.A et al. [24] suggested an attendance system in a university environment using Near-Field Communication (NFC) technology, is a web-based attendance system to improve the current daily attendance registration and to reduce the time spent on recording attendance; it is composed of a web server and NFC components. NFC is based on RFID technology that transfers data in a short distance [25]. 


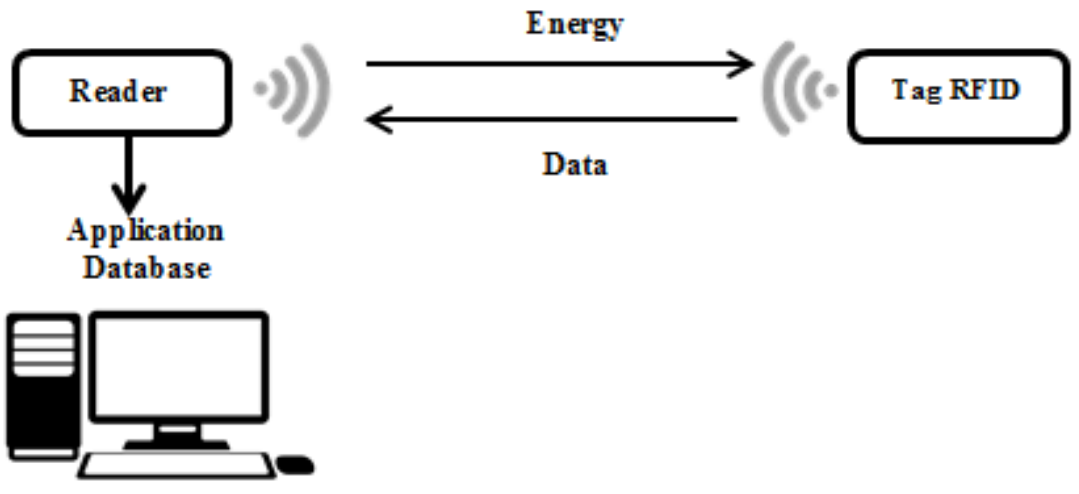

Fig. 3. RFID communication mechanism.

Bluetooth Low Energy (BLE) is a wireless personal area networks combines Microchip and RFID technologies that offer many advantages as shown in Table 2. Is intended to provide very low power consumption compared to conventional Bluetooth [26]. BLE is another technology recently used in school attendance. For instance, Zorić B. et al. [27] proposed a smart attendance management system composed of BLE beacons, a smartphone and a web service. The system design addresses the most issues occurring while tracking student attendance, such as regular cheating attempts.

Among all the technologies mentioned in this section, we have chosen RFID technology due to their reasonable cost and the many positive properties it provides as shown in Table 2.

Table 2. Comparison between technologies

\begin{tabular}{|l|l|l|l|}
\hline & \multicolumn{1}{|c|}{ NFC } & \multicolumn{1}{c|}{ BLE } & \multicolumn{1}{c|}{ RFID } \\
\hline Range & $-15 \mathrm{~cm}$ & $-50 \mathrm{~m}$ & $100 \mathrm{~m}$ \\
\hline Network type & Point to Point & WPAN & Point to Point \\
\hline Frequency & HF & HF/UHF & LF/HF/UHF \\
\hline Set-up time & $0,1 \mathrm{~s}$ & $-9 \mathrm{~s}$ & $0,1 \mathrm{~s}$ \\
\hline Communication & Two way & Two way & One way \\
\hline Power consumption & Very low & Very low & Varies with frequency \\
\hline Cost of device & Very Low & High & Low / High \\
\hline
\end{tabular}

\section{Methods and Theoretical Framework}

The aim of the current study is to create an effective means to record attendance in a way which doesn't hinder learning especially for the high schools as a case study. The systematic review method was implemented to evaluate the current applications on smart attendance systems, as the first phase started with collecting information need through a questionnaire as described in section 2.2. The second phase focused on 
analyzing all available studies on smart attendance systems to get an idea about the best technology used in school attendance and discover how each system has advantages and disadvantages.

A preliminary design of our system was created using RFID technology and ARDUINO board as the main equipment. The web-based attendance system was developed using JAVA JEE programming language and SPRING Framework for establishing the application interface. TOMCAT is used as a web server platform. Students' information and data collection are stored in HSQLDB database.

\subsection{Proposed model architecture}

The overall architecture of our proposed framework consists of three main phases: detection, notification in real time and send missed lessons. In the detection phase, the system captures and collects information about the learners and compares with the student presence file. Afterwards, the system notifies the school administration and the parents in real time with no intervention from the teacher. In the last phase, if the student is absent from the class, the system will send him the missed lessons. As presented in Figure 4 the IoT-Attendance management system uses Ultra High Frequency readers (UHF) that cover a 6 meters area, and passive RFID tags tied to the student's card. The UHF reader starts by detecting the signals related to the student then transmit via ARDUINO board to the web server, in order to check the learner's file. Subsequently, if our system detects the absence of students, a notification is sent to the parents in real time either by Email or SMS and at same time the system can automatically send lessons to absent students by Email.

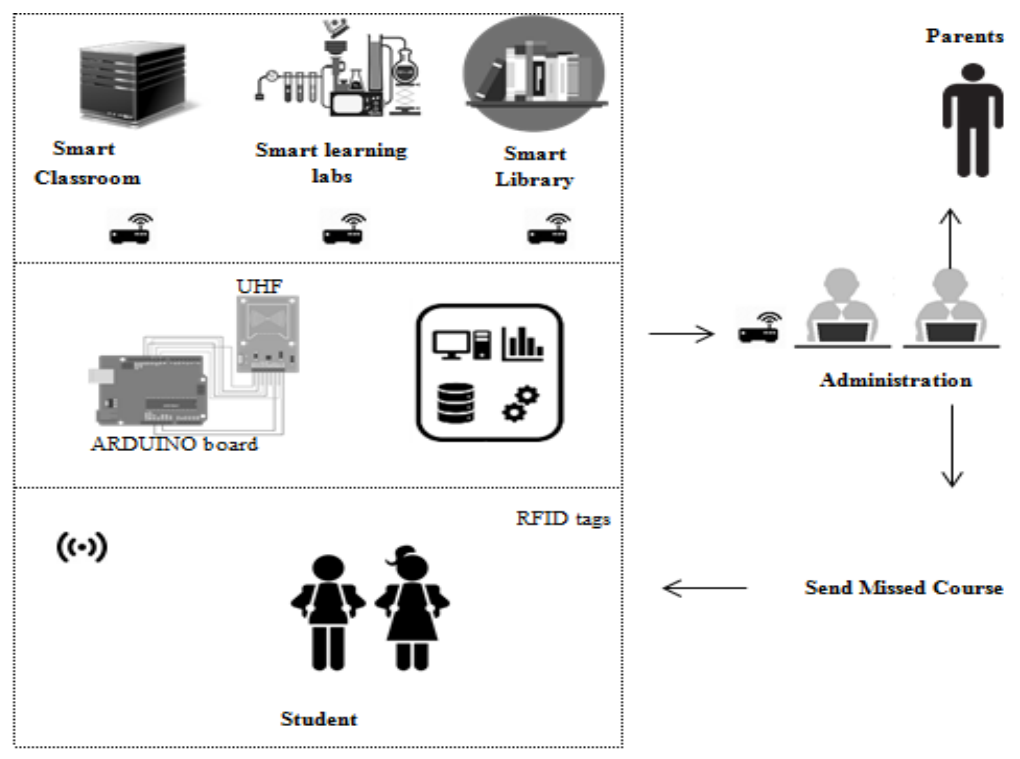

Fig. 4. Architecture of IoT-School attendance 


\subsection{Diagram of IoT-school attendance}

Figure 5 shows and summarizes the basic process of our IoT-School attendance, where the three main phases are illustrated. It's possible for a student to send his card with a friend or another person and be recorded as present while in fact he is absent, to fix this kind of deception we are trying to add a camera to detect the number of persons in the class and compare them with students declared by our system.

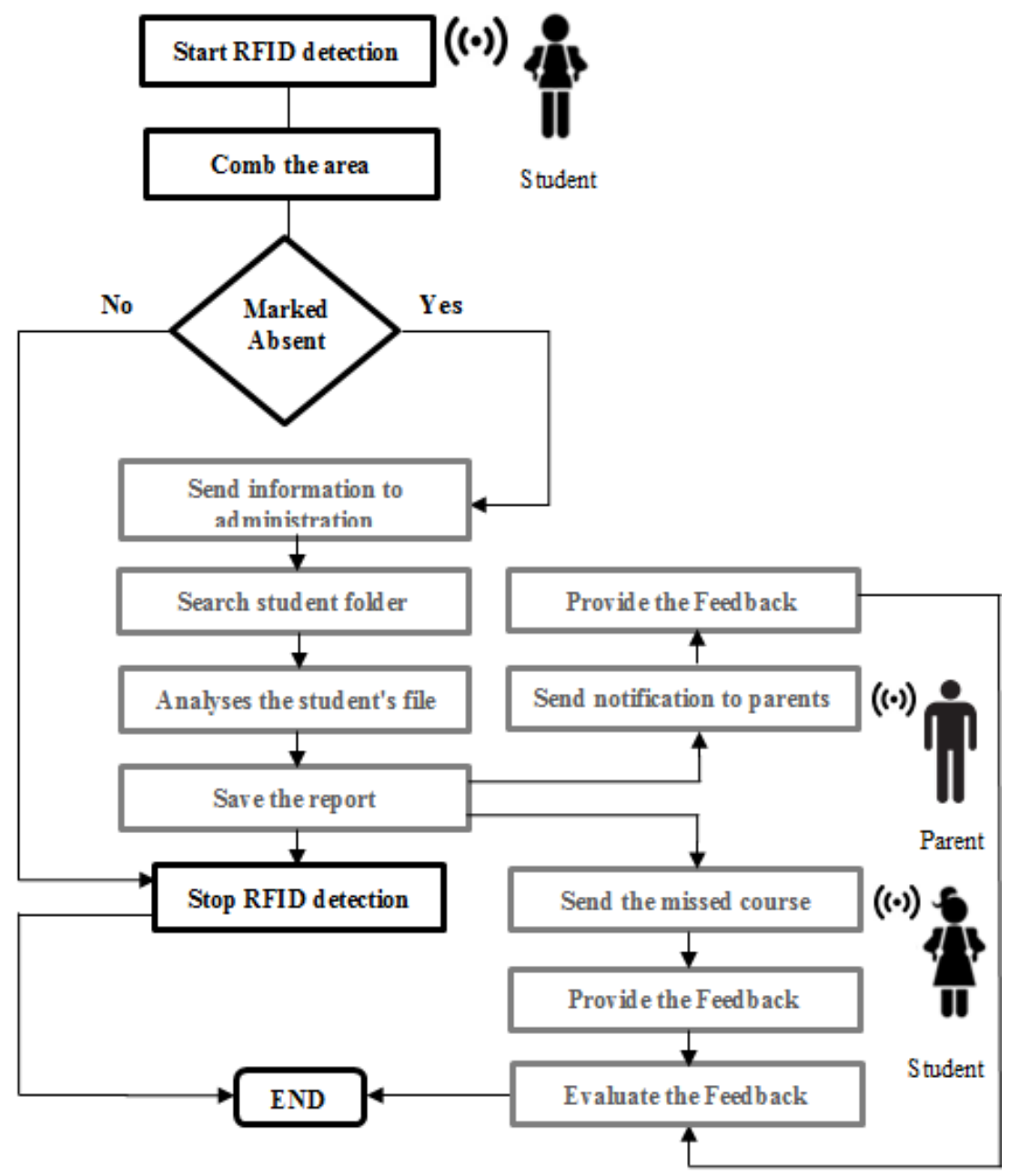

Fig. 5. Diagram of IoT-School Attendance System

\section{Experimental Results and Discussions}

In this section we will highlight evaluation findings, explain our experiment and evaluation method from various aspects. The experimental sample includes two 
groups of students (two classes), where group A contains 38 students and group B contains 36 students. All participants involved in this experiment were scientific students from the same high school and the same level of study. The participants are 1517 years old. It should be noted that the measurements were performed at 7 weeks in the initial stage. The Mann-Whitney U test was used to compare differences between two independent groups (Experimental group and Control group). Where, group A (Experimental group) was subject to the IoT-Attendance system while group B (Control group) was subject to the traditional attendance method. Table 3 shows data extracted from the experiment and shows the results of attendance processing in the seven weeks of testing.

Table 3. Test result before and after the IoT Attendance.

\begin{tabular}{|c|c|c|c|c|c|c|c|c|}
\hline $\begin{array}{c}\text { Week } \\
\text { number }\end{array}$ & Sample & n & S1 Values & Rank A & Sample & n & S2 Values & Rank B \\
\hline 1 & 1A & 37 & 34 & 6 & 1B & 36 & 25 & 1 \\
\hline 2 & 2A & 34 & 34 & 6 & 2B & 35 & 28 & 2 \\
\hline 3 & 3A & 38 & 35 & 8.5 & $3 \mathrm{~B}$ & 34 & 33 & 3.5 \\
\hline 4 & $4 \mathrm{~A}$ & 36 & 36 & 11 & $4 \mathrm{~B}$ & 33 & 33 & 3.5 \\
\hline 5 & $5 \mathrm{~A}$ & 36 & 36 & 11 & $5 \mathrm{~B}$ & 33 & 34 & 6 \\
\hline 6 & 6A & 34 & 37 & 13 & $6 \mathrm{~B}$ & 28 & 35 & 8.5 \\
\hline 7 & 7A & 35 & 38 & 14 & $7 \mathrm{~B}$ & 25 & 36 & 11 \\
\hline
\end{tabular}

$$
\begin{gathered}
U_{A}=n_{A} \cdot n_{B}+\frac{n_{A} \cdot\left(n_{A}+1\right)}{2}-\sum \operatorname{Ranks}_{A}=7.5 \\
U_{B}=n_{A} \cdot n_{B}+\frac{n_{B} \cdot\left(n_{B}+1\right)}{2}-\sum \operatorname{Ranks}_{B}=41.5
\end{gathered}
$$

The test statistic is the smaller of the two values UA and UB. So the UObtained is 7.5. The critical value of Uatp $<.05$ is 8 . Therefore, the result is significant at $p<.05$. Here a task is denoted as UObtained $\leq$ UCritical and we note that during 7 weeks the number of absent students significantly decreased which further proves the successful performance of our system. In this case, the implementation of the IoT-Attendance system was more effective than the traditional method. According to the findings shown in Figure 6, almost absence decreased after the use of IoT-School attendance, except for justified absence. These results include student absence or lateness. 


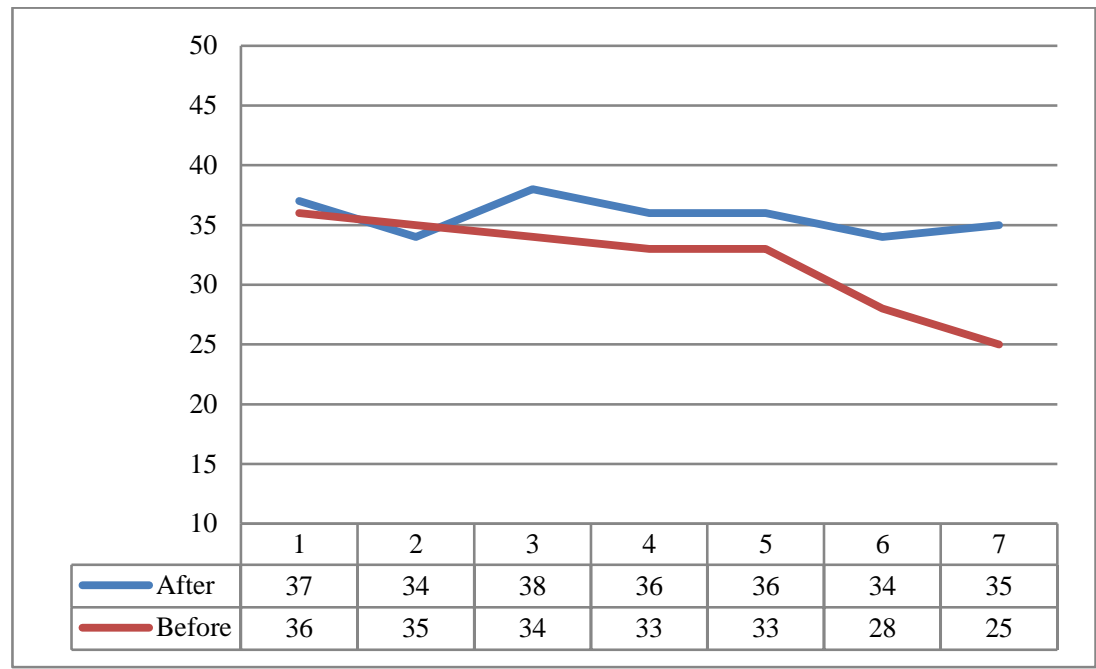

Fig. 6. The results of absenteeism before and after IoT attendance

The results obtained for our system are coherent, optimal and encouraging as shown in Figure 7. A preliminary result after 7 weeks shows that the students discipline increased by $(6 \%)$ and $(8 \%)$ increase in success rate.

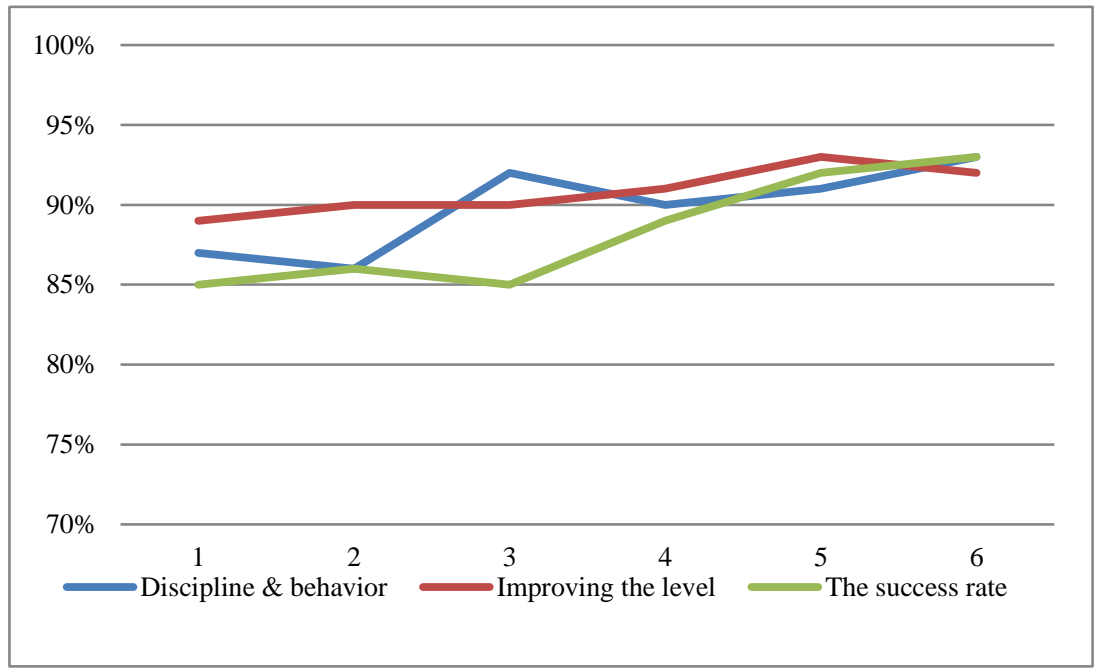

Fig. 7. The reflection of IoT attendance system on the quality of education

Table 4 shows the advantages that IoT-Attendance offers compared to traditional methods. On average, the processing time lasts approximately $2-5 \mathrm{~min}$. The traditional method of treating absenteeism tends to be more tiring, tedious and wastes a lot of time when the number of students increases. 
Table 4. Comparison of different attendance methods.

\begin{tabular}{|c|c|c|c|}
\hline & Teachers & Superintendent & IoT attendance \\
\hline Check Methods & $\begin{array}{l}\text { Traditional methods } \\
\text { (attendance sheet) }\end{array}$ & \begin{tabular}{|l|}
$\begin{array}{l}\text { Traditional methods } \\
\text { (attendance sheets) }\end{array}$ \\
\end{tabular} & Smart System \\
\hline Task properties & $\begin{array}{l}\text { - Laborious } \\
\text { - Routinely } \\
\text { - Manual } \\
\end{array}$ & $\begin{array}{l}\text { - Overwrought } \\
\text { - Routinely } \\
\text { - Manual } \\
\end{array}$ & $\begin{array}{l}\text { - Easy } \\
\text { - Dynamic } \\
\text { - Fast } \\
\end{array}$ \\
\hline Task duration & $\begin{array}{l}(4-6) \\
\mathrm{min} / \text { one class }\end{array}$ & $\begin{array}{l}(30-40) \\
\mathrm{min} / \text { all classes }\end{array}$ & $\begin{array}{l}(2-5) \\
\mathrm{min} / \text { all classes }\end{array}$ \\
\hline Time saving & None & None & YES \\
\hline Mistake & YES & YES & None \\
\hline Real-time-notification & None & None & YES \\
\hline
\end{tabular}

The system will reduce the waste of time during collection of attendance preserve learning time, increase students' performance and will improve school performance, quality of learning, eliminate the duplicate attendance data, achieve maximum discipline for students, and strengthening the relationship between families /schools to control student absenteeism. Also, there are some recommendations to improve our system such as students who use their friends' cards, its necessary to add other mechanisms to fix this deception. In addition, the system must compute the discipline marks from the IoT-Attendance record. Creating these recommendations will affect dramatically the school's digitization, especially in smart attendance systems.

\section{Conclusion and Future Work}

Recent ICT have led to an introduction of innovative modes of teaching and learning on a large scale [28]. The implementation of smart environment as a new paradigm of ICT helps teachers, students and staff to automate the education field [29].

In the current study, we proposed a smart attendance system based on IoT concept by using daily attendance monitoring to check students' absenteeism. The implemented system offers a lot of benefits over traditional system. In traditional method of attendance system, the recording of attendance in classrooms is always done at the expense of the learning time. The IoT-Attendance system help teachers allocate more time to students learning rather than spend their time on traditional recording. The IoT-Attendance evaluate shows that our model is effective and has a potential impact to improve student performance and strengthen collaboration between parents and school to monitor student attendance in the classroom. Moreover, when students miss class, missed lessons can be automatically sent to absent students, which increase learning opportunities for all students and get good marks in their exams. The performance of student is also positively affected by the use of the IoT-Attendance system.

Future work aims to develop a smart guidance system in high school based on IoT, to facilitate academic and professional choices, and to automatically guide students towards an appropriate academic path. 


\section{$7 \quad$ References}

[1] Foutsitzi, S., Asteriadis, S., \& Caridakis, G. (2019). An overview of Affective Models and ICT in Education. 2019 10th International Conference on Information, Intelligence, Systems and Applications (IISA). https://doi.org/10.1109/iisa.2019.8900783

[2] N. Vidakis, A.-K. Barianos, A.-M. Trampas, St. Papadakis, M. Kalogiannakis, and K. Vas ilakis, "Generating Education in-Game Data: The Case of an Ancient Theatre Serious Game," In B. McLaren, R. Reilly, S. Zvacek, \& J. Uhomoibhi (Eds), Proceedings of the 11th International Conference on Computer Supported Education (CSEDU 2019), Vol 1, 36-43, Heraklion, Crete, Greece, 2-4 May, 2019. https://doi.org/10.5220 10007810800360043

[3] Ji-Seong Jeong, Mihye Kim, Kwan-Hee Yoo, (2013). A Content Oriented Smart Education System based on Cloud Computing, International Journal of Multimedia and Ubiquitous Engineering, Vol.8, No.6 pp.313-328. https://doi.org/10.14257/ijmue.2013.8.6.31

[4] Jung, J., Chun, S., Jin, X., \& Lee, K.-H. (2016). Enabling smart objects discovery via constructing hypergraphs of heterogeneous IoT interactions. Journal of Information Science, 44(1), 110-124. https://doi.org/10.1177/0165551516674164

[5] Hicham EL Mrabet, Abdelaziz Ait Moussa, "Smart Classroom Environment Via IoT in Basic and Secondary Education". Transactions on Machine Learning and Artificial Intelligence, Vol 5 No 4 August (2017); p: 274-279. https://doi.org/10.14738/tmlai.54.3191

[6] Gligoric, N., Uzelac, A., \& Krco, S. (2012). Smart Classroom: Real-time feedback on lecture quality. 2012 IEEE International Conference on Pervasive Computing and Communications Workshops. https://doi.org/10.1109/percomw.2012.6197517

[7] Gomez, J., Huete, J. F., Hoyosa, O., Perez, L. and Grigori, D. (2013). Interaction System Based on Internet of Things as Support for Education. The $4^{\text {th }}$ International Conference on Emerging Ubiquitous Systems and Pervasive Networks (EUSPN-2013). Procedia Computer Science 21 2013)) 132 - 139. https://doi.org/10.1016/j.procs.2013.09.019

[8] Songsom, N., Nilsook, P., Wannapiroon, P., Fung, C.C. andWong, K.W. (2019), System architecture of a student relationship management system using Internet of Things to collect Digital Footprint of Higher Education Institutions. International Journal of Emerging Technologies in Learning, 14 (23). pp. 125-140. https://doi.org/10.3991 lijet.v14i23.11066

[9] KassabM, DeFranco J, Laplante P. A systematic literature review on Internet of things in education: Benefits and challenges. J Comput Assist Learn. 2019;1-13. https://doi.org/10.1111/jcal.12383

[10] Kobkiat Saraubon, (2019). Learning Media Repository and Delivery System for Smart Classrooms using IoT and Mobile Technologies, International Journal of Interactive Mobile Technologies (iJIM). Vol 13, No 02, pp. 66-77. https://doi.org/10.3991 lijim.v13i02.9941

[11] Zhi M., Mahinderjit Singh M. (2015) RFID-Enabled Smart Attendance Management System. In: Park J., Pan Y., Kim C., Yang Y. (eds) Future Information Technology - II. Lecture Notes in Electrical Engineering, vol 329. Springer, Dordrecht. https://doi.org/10.1007/978-94-017-9558-6_26

[12] Sánchez López, T., Ranasinghe, D.C., Harrison, M. et al. Adding sense to the Internet of Things. Pers Ubiquit Comput 16, 291-308 (2012). https://doi.org/10.1007/s00779-011$\underline{0399-8}$

[13] Khalid L. (2020) Internet of Things (IoT). In: Software Architecture for Business. Springer, Cham. https://doi.org/10.1007/978-3-030-13632-1_7 
[14] P. P. Ray, A survey on internet of things architectures, Journal of King Saud UniversityComputer and Information Sciences 30 (3) (2018) 291-319. https://doi.org/10.1016 /j.jksuci.2016.10.003

[15] Zhu, Z., Yu, M. \& Riezebos, P. A research framework of smart education. Smart Learn. Environ. 3, 4 (2016). https://doi.org/10.1186/s40561-016-0026-2

[16] Dickerson, S. J. (2017). A comprehensive approach to educating students about the internet-of-things. 2017 IEEE Frontiers in Education Conference (FIE). https://doi.org/10.1109/fie.2017.8190533

[17] Borg J., Scott-Young C.M., Turner M. (2019) Smarter Education: Leveraging Stakeholder Inputs to Develop Work Ready Curricula. In: Uskov V., Howlett R., Jain L. (eds) Smart Education and e-Learning 2019. Smart Innovation, Systems and Technologies, vol 144. Springer, Singapore, pp. 51-61. https://doi.org/10.1007/978-981-13-8260-4_5

[18] Bakken, J. P., Varidireddy, N., \& Uskov, V. L. (2019). Smart University: Software/Hardware Systems for College Students with Severe Motion/Mobility Issues. Smart Innovation, Systems and Technologies, 471-487. https://doi.org/10.1007/978-981-13$\underline{8260-4 \_42}$

[19] A. Zhamanov, Z. Sakhiyeva, R. Suliyev and Z. Kaldykulova, "IoT smart campus review and implementation of IoT applications into education process of university," 2017 13th International Conference on Electronics, Computer and Computation (ICECCO), Abuja, 2017, pp. 1-4. https://doi.org/10.1109/ICECCO.2017.8333334

[20] H. EL MRABET, A. AIT MOUSSA. (2019), Smart School Guidance and Vocational Guidance System Through the Internet of Things. In Proceedings of ACM Networking Information Systems and Security, Rabat, Morocco, March 27-29, 2019 (NISS '19), 5 pages. https://doi.org/10.1145/3320326.3320404

[21] Courtad C.A. (2019) Making Your Classroom Smart: Universal Design for Learning and Technology. In: Uskov V., Howlett R., Jain L. (eds) Smart Education and e-Learning 2019. Smart Innovation, Systems and Technologies, vol 144. Springer, Singapore. https://doi.org/10.1007/978-981-13-8260-4_44

[22] Q. Miao, F. Xiao, H. Huang, L. Sun and R. Wang, "Smart attendance system based on frequency distribution algorithm with passive RFID tags," inTsinghua Science and Technology, vol. 25, no. 2, pp. 217-226, April 2020. https://doi.org/10.26599/TST.2018.9010141

[23] S. N. Shah and A. Abuzneid, "IoT Based Smart Attendance System (SAS) Using RFID," 2019 IEEE Long Island Systems, Applications and Technology Conference (LISAT), Farmingdale, NY, USA, 2019, pp. 1-6. https://doi.org/10.1109 /LISAT.2019.8817339.

[24] Ayu, M.A., Ahmad, B.I.: TouchIn: An NFC Supported Attendance System in a University Environment. International Journal of Information and Education Technology 4(5), 448453 (2014). https://doi.org/10.7763/IJIET.2014.V4.448

[25] Bin Mohd Nasir M.A.H., bin Asmuni M.H., Salleh N., Misra S. (2015) A Review of Student Attendance System Using Near-Field Communication (NFC) Technology. In: Gervasi O. et al. (eds) Computational Science and Its Applications -- ICCSA 2015. ICCSA 2015. Lecture Notes in Computer Science, vol 9158. Springer, Cham. https://doi.org/10.1007/ 978-3-319-21410-8_56

[26] Riya Lodha, Suruchi Gupta, Harshil Jain and Harish Narula, "Bluetooth Smart Based Attendance Management System", Procedia Computer Science, Volume 45, 2015, Pages 524-52. https://doi.org/10.1016/j.procs.2015.03.094

[27] B. Zorić, M. Dudjak, D. Bajer and G. Martinović, "Design and development of a smart attendance management system with Bluetooth low energy beacons," 2019 Zooming Innova- 
tion in Consumer Technologies Conference (ZINC), Novi Sad, Serbia, 2019, pp. 86-91, https://doi.org/10.1109/ZINC.2019.8769433

[28] Papadakis S., Kalogiannakis M., Sifaki E., Vidakis N. (2018) Access Moodle Using Smart Mobile Phones. A Case Study in a Greek University. In: Brooks A., Brooks E., Vidakis N. (eds) Interactivity, Game Creation, Design, Learning, and Innovation. ArtsIT 2017, DLI 2017. Lecture Notes of the Institute for Computer Sciences, Social Informatics and Telecommunications Engineering, vol 229. Springer, Cham. https://doi.org/10.1007/978-3-31976908-0_36

[29] Burd, B., Guerra, J. G., Elahi, A., Russell, I., Barker, L., Pérez, A. F., Tudor, L. (2017). The Internet of Things in CS Education. Proceedings of the 2017 ACM Conference on Innovation and Technology in Computer Science Education - ITiCSE '17. https://doi.org/10.1145/3059009.3081331

\section{Authors}

Hicham El Mrabet is a secondary school teacher in computer science and parttime trainer at the specialized institute of applied technology of Berkane, Morocco, and a current PhD student at Faculty of Sciences, Mohammed First University Oujda, Morocco. Hold a Master degree in telecommunication and engineering systems from Abdelmalek Essaadi University of Tétouan, Morocco, and a Bachelor degree in systems and networks from Hassan First University, Settat, Morocco. He has seven years of experience in education and he was a Microsoft Office specialist trainer at the Regional Academy of Education of Oujda. Email: hi.elmrabet@gmail.com

Abdelaziz Ait Moussa is a professor of computer science at Mohammed first university, with more than 10 years of participation in the improvement of teaching using educational engineering. He has published many articles about the brain computer interface, intelligent tutors and smart learning environment. He has published articles on the use of platforms in the Moroccan university. He has participated in the creation of a training unit in the Faculty of Science to help teachers submit their courses online. He was also involved in the creation of the Masters in Education and Educational Technology. In 2013, he obtained the Diploma of the MASTER ACCREDITE (Analysis, Design and Research in the field of Technological Engineering in Education) from the cirgy-pontoise university. Currently, he is the Director of ICTE Laboratory. Email: $\underline{\text { a_aitmoussa@yahoo.fr }}$

Article submitted 2020-04-04. Resubmitted 2020-05-20. Final acceptance 2020-05-20. Final version published as submitted by the authors. 